\title{
A systematic review of the effects of strength training in patients with fibromyalgia: clinical outcomes and design considerations
}

\author{
Alexandro Andrade ${ }^{1,2^{*}}$ (D) , Ricardo de Azevedo Klumb Steffens ${ }^{1,2,3}$ (D), Sofia Mendes Sieczkowska ${ }^{1,2}$ (D), \\ Leonardo Alexandre Peyré Tartaruga ${ }^{4,5}$ (D) and Guilherme Torres Vilarino ${ }^{1,2}$ (D)
}

\begin{abstract}
Background: Fibromyalgia (FM) is characterized by chronic and generalized musculoskeletal pain. There is currently no cure for FM, but palliative treatments are available. One type of treatment is strength training (ST). However, there is a need for more information on optimal training protocols, intensity, and volume needed to improve symptoms. The aim of this study was to analyze the effects of ST in the treatment of FM through a systematic review of experimental research.

Methods: Medical Subject Headings search terms and electronic databases including Scientific Electronic Library Online, PubMed, Science Direct, Web of Science, and Physiotherapy Evidence Database were used to identify studies.

Results: The inclusion criteria were met by 22 eligible studies. Most of the studies were conducted in the United States (36\%), Finland (23\%), Brazil (18\%), and Sweden (18\%). The studies showed that ST reduces the number of tender points, fatigue, depression, and anxiety, and improves sleep quality and quality of life in patients with FM. The intervention period ranged from 3 to 21 weeks, with sessions performed 2 times a week in $81.81 \%$ of the studies, at initial intensities of $40 \%$ of 1 -repetition maximum. The repetitions ranged from 4 to 20 , with no specific protocol defined for ST in FM.
\end{abstract}

Conclusion: The main results included reduction in pain, fatigue, number of tender points, depression, and anxiety, with increased functional capacity and quality of life. Current evidence demonstrates that ST is beneficial and can be used to treat FM.

Trial registration: CRD42016048480.

Keywords: Fibromyalgia, Resistance training, Health, Exercises, Therapy, Rehabilitation

\section{Background}

Fibromyalgia (FM) is a chronic disease characterized by generalized skeletal muscle pain [1,2], and other common symptoms include fatigue, sleep disorders, depression, and excessive anxiety [3-6]. The pathogenesis of FM is still not well understood [7], and FM is

\footnotetext{
* Correspondence: alexandro.andrade.phd@gmail.com

${ }^{1}$ Health and Sports Science Center, CEFID / Santa Catarina State University UDESC, Florianópolis, SC, Brazil

${ }^{2}$ Laboratory of Sports and Exercise Psychology - LAPE, Florianópolis, SC, Brazil Full list of author information is available at the end of the article
}

considered by some researchers to be a neurobiological disease caused by abnormal processing of pain [8]. Owing to the lack of markers that can identify the disease, the diagnosis is made through clinical examination, according to the guidelines of the American College of Rheumatology [1,3].

As FM has no cure, treatments are palliative, and multidisciplinary approaches involving the use of medications, physical exercise (PE), and psychological treatments are recommended [4, 9-12]. PE has been advised in several studies and guidelines for the treatment of FM

(c) The Author(s). 2018 Open Access This article is distributed under the terms of the Creative Commons Attribution 4.0 International License (http://creativecommons.org/licenses/by/4.0/), which permits unrestricted use, distribution, and 
[13-16], and the inclusion of aerobic, resistance, and water exercises has been strongly recommended $[5,15-$ 17]. The severity of FM symptoms can affect the level of physical fitness, and patients commonly perform little physical activity because of pain [18-20].

The relationship between PE and FM has been investigated, and strength training (ST) has been compared with other PE modalities. Studies have shown that ST has favorable results on pain, sleep, depression, and the number of tender points $[17,21]$. However, studies on the effect of PE present poor quality evidence owing to small sample sizes and methodological problems [22, 23]. Recent studies have attempted to better understand the effects of ST in patients with FM [21, 24-26]. However, research has emphasized physical aspects with conflicting results $[27,28]$. Despite recent research on the effects of ST in patients with FM, the duration, frequency, and intensity required to improve the symptoms remain unknown because the protocols differ among studies [29-31]. Thus, there is no consensus on the use of ST in clinical practice. The aim of this study was to analyze the effects of ST in the treatment of FM through a systematic review of experimental research.

\section{Methods}

The present study followed the PRISMA (Preferred Reporting Items for Systematic Reviews and Meta-Analyses) guidelines [32]. The PRISMA Statement is a protocol that guides the construction of systematic reviews in a transparent and consistent manner using a checklist of 27 items and a 4-phase flow diagram [33]. This systematic review was registered as CRD42016048480 in the International Prospective Register of Systematic Reviews (PROSPERO) [34]. A primary goal of PROSPERO is to make known the intention to conduct a systematic review, in order to reduce duplication and to facilitate transparency in the review process [35].

\section{Eligibility criteria}

In order to include the entire publication period, no time limit was set. The eligibility criteria were determined according to the PICOS (Population, Intervention, Comparison, Outcomes, Setting) strategy.

\section{Population}

Adults 18 years and older with a diagnosis of FM according to the 1990 criteria of the American College of Rheumatology (1).

\section{Intervention}

Any intervention with ST or resistance training for patients with FM was included. We excluded studies with combined interventions, such as those with ST combined with aerobic training.

\section{Comparison}

With any other type of group (such as sedentary controls and healthy controls) and with other types of intervention (such as aerobic exercise and flexibility exercise).

\section{Outcomes}

All possible effects of ST and the intervention protocols used in the studies in patients with FM.

\section{Type of study}

Randomized or non-randomized trials reporting clinical outcomes demonstrating the effects of ST. The frequency of ST and the extent to which ST was provided were the minimum necessary data for a research to be defined as an intervention study. Revised articles, dissertations, theses, and congress abstracts were excluded.

\section{Information sources}

The studies were identified through electronic databases, including PubMed, Science Direct, Web of Science, Physiotherapy Evidence Database, and Scientific Electronic Library Online. The last survey was conducted in December 2017.

\section{Search strategy}

The search terms were defined by the researchers using the Medical Subject Headings (Table 1), and the search strategy in the PubMed database is shown in Additional file 1.

\section{Study identification}

The searches and selection of articles were independently performed by 2 researchers; in case of disagreement, a third party was asked to make the final decision. An initial analysis was performed based on reading the title. From these selected articles, the abstracts were read and the articles included in the review were read in their entirety. A review of the references and citations of these articles was also carried out in order to identify other potentially relevant studies. From the selected studies, an analysis of the use of ST for the treatment of patients with FM was performed.

\section{Data extraction}

For the analysis and discussion of the results, the following data were extracted: author and study design; study participant number, age, sex, and treatment group; type of exercise, time of intervention, intensity, and adherence (based on either the number of attending patients at the beginning and end of the study or from data provided by the authors); and conclusions of the study.

\section{Quality of study and risk of Bias}

This systematic review evaluated the quality of the included studies and the risk of bias using the Cochrane 
Table 1 Search terms used in databases

\begin{tabular}{ll}
\hline Terms & Descriptors \\
\hline 1. Disease & "Fibromyalgia" \\
2. Exercise & "Resistance Training" OR "Strength Training" OR "Strength \\
& $\begin{array}{l}\text { Training Program*" OR "Training Resistance" OR } \\
\text { "Strengthening Program" }\end{array}$ \\
Combination & $\# 1$ AND \#2 \\
\hline
\end{tabular}

Collaboration Risk of Bias tool [36], which includes criteria to identify bias in the selected studies that can interfere with the interpretation and conclusion. Bias risk assessment was performed by 2 researchers. The kappa concordance index [37] between the reviewers for each of the criteria was determined, and differences were resolved by consulting a third reviewer for a final opinion.

\section{Results}

\section{Identification and selection of studies}

The first stage of selection using the databases identified 211 studies, with 1 additional study manually inserted. Sixty-two duplicate studies were excluded and 48 abstracts were selected after reading the titles. At the abstract review stage, 17 studies were excluded, of which 9 used combined exercise, 7 were congress abstracts, and 1 did not evaluate patients with FM. In the fourth stage, the complete texts of 31 studies were read; 5 were excluded because of the intervention protocol, 1 was a short communication, and 1 was a congress article. Thus, 22 studies were selected for the analysis, as shown in Fig. 1.

\section{Characteristics of included studies}

Of the 22 studies included in the review, the oldest was published in 2001 [38] and the most recent was published in 2017 [24, 39, 40] (Table 2). Most of the studies were conducted in the United States $(36 \%, n=8)$, followed by Finland (23\%, $n=5)$, Brazil $(18 \%, n=4)$, Sweden $(18 \%, n=4)$, and Turkey $(5 \%, n=1)$. Women aged 18-65 years comprised the total sample, and the main variables analyzed were pain, strength, muscular activity, functional capacity, fatigue, quality of life, and sleep $[24,25,27,29,38,39,41-44]$. Among the tests used in the evaluations, the Fibromyalgia Impact Questionnaire, which evaluates the impact of FM on quality of life, was used in most of the studies [25, 27-29, 31, 45-48]. To measure strength, the 1-repetition maximum (1RM) was the most used test $[27-29,31,38,49,50]$ and studies that verified muscle activity used electromyography [38, 41, 51-53]. The visual analogue scale was used to evaluate pain in most of the studies [29, 41, $42,45,48,53]$. Concerning adherence, most of the studies did not provide this information. Therefore, adherence was calculated based on the patients' attendance, and an average adherence percentage of $84 \%$ (range, 54$100 \%)$ was obtained. Five studies provided the average attendance rate, ranging from 71 to $100 \%$.

\section{Summary of evidence and practical implications}

The analysis of the results revealed that ST reduced the symptoms of patients with FM, such as pain, fatigue, number of tender points, depression, and anxiety, with improved functional capacity and quality of life [24, 25, 27, 29, 38, 39, 41, 42] (Table 2), despite the different training protocols used.

When analyzing the training protocol, $81.81 \%$ of the studies submitted the patients to interventions twice a week, whereas only $13 \%$ (3 studies) submitted the patients to 3 sessions per week and 1 study verified the effect of a single session. Concerning the intervention time, the shorter studies lasted for 3 weeks whereas the longer studies lasted for 21 weeks. Most of the studies had an intervention time of 21 (22.72\%), 12 (22.72\%), 16 (18.18\%), and 15 (18.18\%) weeks. The studies used similar training protocols, starting with $40 \%$ of $1 \mathrm{RM}$ and progressing to $85 \%$. During the training, exercises using machines and free weights worked the large and small muscle groups.

Pain was the most studied variable, showing a reduction after ST [27, 29, 30, 45, 53-55]. No study reported increased pain after or during the intervention period. Kayo et al. [48] found at the end of 16 weeks of intervention that only $41.4 \%$ of patients in the ST group were using pain medication, whereas in $80 \%$ of the patients in the control group regularly used pain medication. Other well-analyzed variables were strength, quality of life, heart rate variability (HRV), and depression. With regard to muscle strength, increases between 33 and 63\% were observed after 21 and 16 weeks [41, 49]. In terms of the variability of heart rate, the effects of ST on patients with FM presented controversial results; however, the evidence shows little effect on this variable [49]. Studies analyzing quality of life and functionality showed that ST is effective in improving these variables [28, 29, 31, 41, 42, 45].

The most investigated psychological variable was depression. The studies of Jones et al. [45], Gavi et al. [29], and Assumpção et al. [40] showed that ST reduces depressive symptoms; however, the study of Ericsson et al. [25] did not find a significant difference after 15 weeks of intervention.

We also analyzed the results related to sleep quality. Andrade et al. [24] found that sleep disorders were reduced after ST and that sleep correlated with pain. The results of Ericsson et al. [25] also disclosed that ST yielded better results than relaxation sessions in improving sleep quality. In addition, another important result is that patients with FM presented similar responses to 


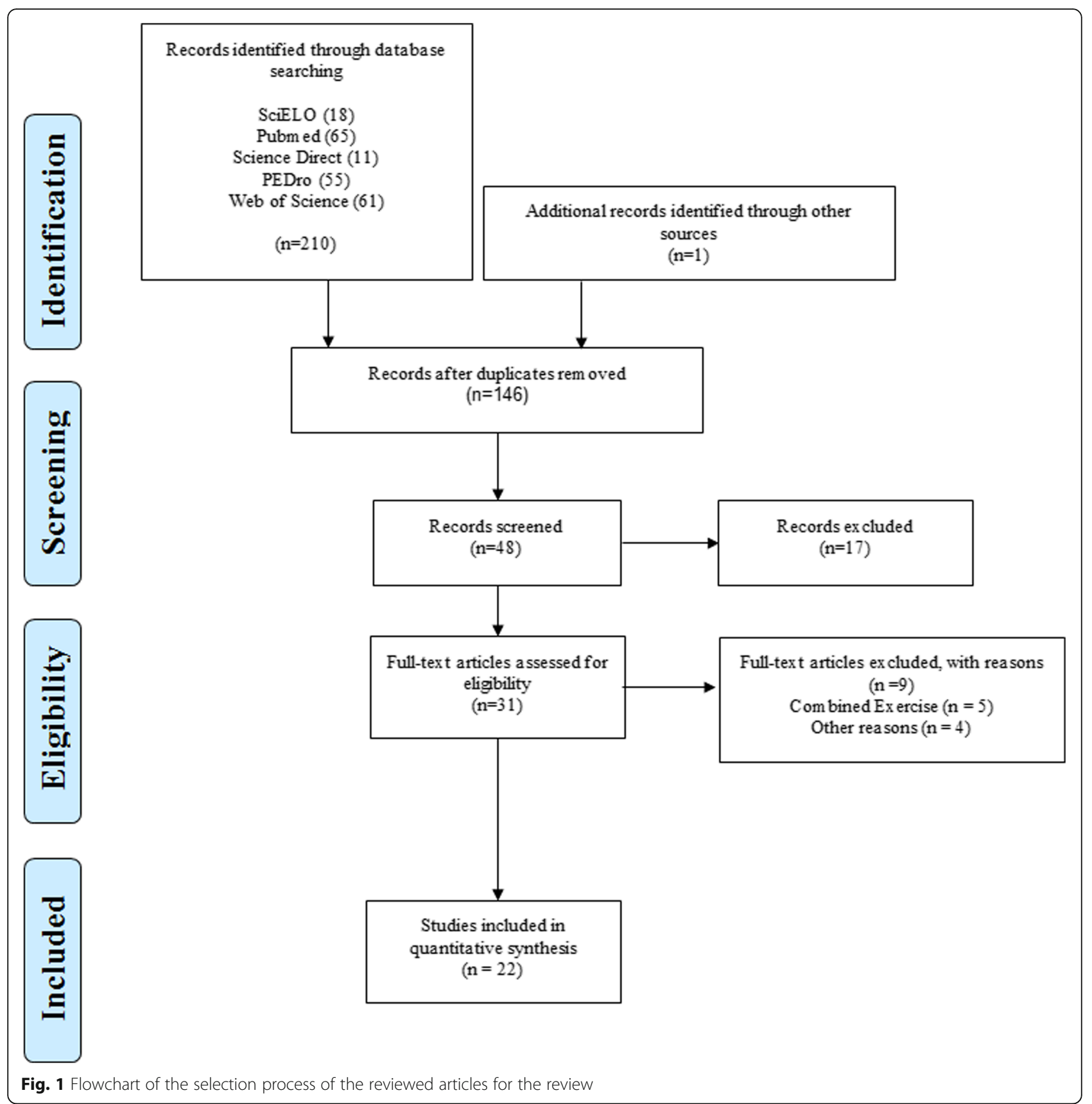

those of healthy persons; thus, they recommended ST to assist in the treatment of patients.

The intervention protocols, results, and conclusions of each study are presented in Table 2.

\section{Quality of studies and risk of Bias}

The kappa concordance index between the two reviewers was $87.1 \%$ for all criteria. Of the 22 studies, 13 had low risk of adequate sequence generation bias; four were unclear regarding the risk of adequate sequence generation bias and six were not randomized. Only four studies had low risk of allocation concealment bias. Ten studies had a high risk of blinded participant bias; only four had a low risk and eight were unclear. Twenty-one studies presented low risk of incomplete data bias. Similar findings were noted for selective results bias; only two studies were unclear. The descriptions of interventions (characteristics of exercises) were another source of bias, with only two studies having a high risk (Fig. 2).

\section{Discussion}

This systematic review aimed to analyze the efficacy of ST in the treatment of FM by examining the existing experimental research. The studies showed that the intervention 
Table 2 Characteristics and results of experimental studies with strength training for patients with fibromyalgia syndrome

\begin{tabular}{lllll}
\hline $\begin{array}{l}\text { Study and } \\
\text { Design }\end{array}$ & Sample & Intervention & Results & Conclusion \\
\hline Hakkinen & 21 women & Duration: 21 weeks; & FM subjects increased their maximal & A similar maneuverability of the \\
et al., (2001); & with FM & Weekly frequency: $2 ;$ & and explosive strength and EMG & neuromuscular system occurs in \\
RCT & (ST and CG) & Repetitions: Initially & activity to the same extent as the HC & women with FM and healthy \\
& e 12 HC & 15-20, from the 15th & group. Moreover, the progressive & women. ST is safe and can be \\
& Age & week; $5-10$ & strength training showed immediate & used to decrease the impact of \\
& TF: $39 \pm$ & Exercises: Supine, squats, & benefits on subjectively perceived & FM in the neuromuscular system \\
& 6 fors & extension and flexion of & fatigue, depression, and neck pain of &
\end{tabular}

years

CG: $37 \pm$

5 years

GS: $37 \pm$

6 years

$\begin{array}{lll}\begin{array}{l}\text { Hakkinen } \\ \text { et al., (2002); }\end{array} & \text { 21 women } & \text { Duration: } 21 \text { weeks; } \\ \text { RCT } & \text { (ST and CG) } & \text { Weekly frequency: 2; Series: 3-5 } \\ \text { and } 12 \text { HC } & \text { series per exercise; Intensity: } \\ & \text { Age } & \text { Initially 10-20, from the 14th } \\ & \text { TF: } 39 \pm & \text { week; } 5-8 . \\ 6 \text { years } & \text { Exercises: leg press, extension } \\ \text { CG: } 37 \pm & \text { and flexion of the knee, elbow } \\ & 5 \text { years } & \text { and trunk, pulled high, adduction } \\ \text { GS: } 37 \pm & \text { and abduction of the legs } \\ 6 \text { years } & \text { Adherence to ST: 100\% }\end{array}$

Jones et al., 68 women Duration: 12 weeks;

(2002); RCT (ST and Weekly frequency: 2 Initially 1 series FLEX): of $4-5$, and progressively up to 12 Age $\quad$ Exercises: The main muscle groups TF: $49.2 \pm$ 6.36 years CG: $46.4 \pm$ 8.56 years specified. Adherence to ST:85\%

$\begin{array}{ll}\text { Valkeinen } & 36 \text { women } \\ \text { et al., (2004); } & (26 \mathrm{FM} \text { and } \\ \text { RCT } & 10 \mathrm{HC}) \\ & \text { Age } \\ & \text { ST: } 60.2 \pm \\ & 2.5 \text { years } \\ & \text { CG: } 59.1 \pm \\ & 3.5 \text { years } \\ & \text { HC: } 64.2 \pm \\ & 2.7 \text { years }\end{array}$

Duration: 21 weeks;

Weekly frequency: 2; Initially 3 series of 15-20 progressively up to 4 series of 8-12 and up to 5 series of 5-10 . Exercises: The main muscle groups were worked, but exercises were not specified.

Adherence to ST: 100\%

HC: 64.2 fatigue, depression, and neck pain of training patients with FM.

Maximal force increased by $18 \pm 10 \%$ in the FM group, and by $22 \pm 12 \%$ in the $\mathrm{HC}$, while in the $\mathrm{CG}$ it remained unchanged. Maximum integrated EMG of the agonists ( $\mathrm{VL}+\mathrm{VM} / 2)$ increased in $\mathrm{HC}$ by $22 \%$ and in the FM by $19 \%$. Significant increases in the CSA of the QF were observed at 5 to $12 / 15$ femur in FM and at 3 to 12/15 femur in $\mathrm{HC}$, while in FM the CSA remained unchanged. A significant acute increase took place in the mean concentration of $\mathrm{GH}$ at pre-training in $\mathrm{HC}$ and in the $\mathrm{FM}$, while at post-training the elevations after the loading remained elevated up to 15 min in $\mathrm{HC}$ and up to 30 min post-loading in the FM.

No statistically significant differences between groups were found on independent t tests. Paired t tests revealed twice the number of significant improvements in the strengthening group compared to the stretching group. Effect size scores indicated that the magnitude of change was generally greater in the strengthening group than the stretching group.

The mean increases in maximal extension force during the training period in groups $\mathrm{FM}$ and in $\mathrm{HC}$ were $32 \pm 33 \%$ and $24 \pm 12 \%$ respectively and those of flexion were $13 \pm 20 \%$ and $24 \pm 17 \%$. Explosive force of the extensors increased in both FM and in $\mathrm{HC}$. The integrated EMGs of the vastus lateralis and medialis muscles increased in both FM and HC. Muscle forces and EMGs in group CG remained at the basal level. Walking speed, stair-climbing time and the HAQ index improved in group FM. The changes in the number of tender points and in perceived symptoms were in favors of the training group FM.

All patients were able to complete the training. In FM strength training led to increases of $36 \%$ and $33 \%$ in maximal isometric and concentric forces, respectively. The CSA increased by $5 \%$ and the EMG activity in isometric action by $47 \%$
The time of neuromuscular and ST adaptations and the basal levels of anabolic hormones in women with FM are similar to healthy women

The ST group decreased the total pain score, the number of tender points, increased leg strength, shoulder strength, improved quality of life and reduced depression. ST showed better results than FLEX.

It improved the functional capacity and the strength in the extensor and flexor muscles of the knee in both groups submitted to the TF (FM and healthy). Patients with FM respond similarly to TF that healthy people of the same age.

The ST increases strength, crosssectional area and voluntary muscular activation in elderly women with FM. Patients with FM can be submitted to higher intensities without increasing symptoms 
Table 2 Characteristics and results of experimental studies with strength training for patients with fibromyalgia syndrome (Continued)

\begin{tabular}{|c|c|c|c|c|}
\hline $\begin{array}{l}\text { Study and } \\
\text { Design }\end{array}$ & Sample & Intervention & Results & Conclusion \\
\hline & & number of dropouts & $\begin{array}{l}\text { and in concentric action by } \\
57 \% \text {. Basal serum hormone } \\
\text { concentrations remained } \\
\text { unaltered during strength } \\
\text { training. The subjective } \\
\text { perceived symptoms } \\
\text { showed a minor decreasing } \\
\text { tendency (ns). No statistically } \\
\text { significant changes occurred } \\
\text { in any of these parameters } \\
\text { in CG. }\end{array}$ & \\
\hline
\end{tabular}

$\begin{array}{ll}\text { Kingsley } & 29 \text { women } \\ \text { et al., (2005); } & \text { (ST and CG); } \\ \text { RCT } & \text { Age } \\ & \text { ST: } 45 \pm 9 \text { years } \\ & \text { GC: } 47 \pm 4 \text { years }\end{array}$

$\begin{array}{ll}\text { Valkeinen } & 23 \text { women } \\ \text { et al., (2006); } & (13 \text { ST and } 10 \text { CG) } \\ \text { Non RCT } & \text { Age } \\ & \text { ST: } 60 \pm 2 \text { years } \\ & \text { CG: } 54 \pm 3 \text { years }\end{array}$

Bircan et al. 26 women

(2008); RCT (ST and AE)

Age

ST: $46 \pm 8,5$ years

AE: $48.3 \pm 5.3$ years

Duration: 12 weeks;

Weekly frequency: $2 ; 1$ serie of $8-12$ Intensity: 60 to $80 \%$ of 1RM

Exercises: Supine, extension and

flexion of knee and elbow, low row,

shoulder and lumbar development

Adherence to ST: 54\%

Duration: 21 weeks;

Weekly frequency: 2 Intensity: Started with $50 \%$ of $1 \mathrm{RM}$ and progressively up to $80 \%$; Exercises: two Exercises for knee extensors and $4-5$ Exercises for the rest of the body

Adherence to ST: $100 \%$

Duration: 8 weeks

Weekly frequency: 3 Initially 1 serie of 4 repetitions and progressively up to 12 repetitions; Exercises were not specified, however, free weights were used and the patient's body weight

Adherence to ST: $100 \%$

$\begin{array}{ll}\text { Figueroa } & 19 \text { women } \\ \text { et al. (2008); } & (10 \mathrm{FM} \text { and } 9 \mathrm{HC}) \\ \text { RCT } & \text { Age } \\ & \text { ST:50 } \pm 10 \text { years } \\ & \text { HC: } 49 \pm 8 \text { years }\end{array}$

Duration: 16 weeks

Weekly frequency: 2

1 serie of 8-12 repetitions; Intensity: Initially 50\% 1RM and progressively up to $80 \%$;

Exercises: Supine, knee extension and flexion, Leg press, low row, shoulder development (performed on machine)

Adherence to ST: $67 \%$
The strength group significantly improved upper and lower body strength. And upper-body functionality measured by the Continuous-Scale Physical Functional Performance test improved significantly after training. Tender point sensitivity and fibromyalgia impact did not change.

The ST led to large increases in maximal force and EMG activity of the muscles and contributed to the improvement in loading performance (average load/set) at week 21. The fatiguing loading sessions typically applied in strength training before and after the experimental period caused remarkable and comparable acute decreases in maximal force and increases in blood lactate concentration in both groups. Acute exercise-induced muscle pain increased similarly in both groups, and the pain level in women with FM was lowered after the 21-week training period.

There were significant improvements in both groups regarding pain, sleep,

fatigue, tender point count, and fitness after treatment. HAD-depression scores improved significantly in both groups while no significant change occurred in HAD-anxiety scores. Bodily pain subscale of SF-36 and physical component summary improved significantly in the AE group, whereas seven subscales of SF-36, physical component summary, and mental component summary improved significantly in the ST group.

RR interval, total power, log transformed $(L n)$ squared root of the standard deviation of RR interval (RMSSD), lowfrequency power and BRS were lower, and $H R$ and pulse pressure were higher in women with FM than in healthy controls. After ST, mean (SEM) total power increased, RMSSD increased and Ln of high-frequency power increased in women with FM. Upper and lower body muscle strength increased by $63 \%$ and $49 \%$, and pain perception decreased by $39 \%$ in women with FM. There were no changes in BRS, HR and BP after ST.

Variables were similar in both groups
At the end of study was a significant increase in muscle strength and improvement in functional capacity components in the ST group.

An increase in maximal strength, blood lactate concentration and decrease in pain of the ST group was observed.

Aerobic exercise and strengthening exercise were similarly effective at improving symptoms, tender point count, fitness, psychological status, and quality of life in fibromyalgia patients.

The ST improves heart rate variability, parasympathetic activity, pain and the strength of women with FM with autonomic dysfunction.

The results showed lower muscle 
Table 2 Characteristics and results of experimental studies with strength training for patients with fibromyalgia syndrome (Continued)

\begin{tabular}{lllll}
\hline $\begin{array}{l}\text { Study and } \\
\text { Design }\end{array}$ & Sample & Intervention & Results & Conclusion \\
\hline et al. (2009); & (FM and HC) & One session & at rest. HFnu decreased in & strength in the FM group and \\
Non RCT & Age & 30 min of ST, 1 serie of 12; & controls and increased in & after acute ST, women with FM \\
& 48,0 years & Exercises: 10 exercises, were & women with FM post. LFnu & responded differently from \\
& (21-59 years) & not specified. & increased in controls and & controls, demonstrated by lower \\
& & Adherence to ST: 100\% & decreased in women with FM. & sympathetic and higher vagal \\
& & The LFnu/HFnu ratio increased & modulation without altering \\
& & in controls with no change in & baroreceptor reflex sensitivity.
\end{tabular}

$\begin{array}{ll}\text { Panton } & 21 \text { women } \\ \text { et al. (2009); } & \text { (ST e ST-C); } \\ \text { RCT } & \text { Age } \\ & \text { ST: } 50 \pm 7 \text { years } \\ & \text { ST-C: } 47 \pm 12 \text { years }\end{array}$

$\begin{array}{ll}\text { Kingsley } & 29 \text { women } \\ \text { et al. (2010); } & \text { (9 FM and } 20 \mathrm{HC}) \\ \text { Non RCT } & \text { Age } \\ & \text { FM: } 42 \pm 5 \text { years; } \\ & \text { HC: } 45 \pm 5 \text { years }\end{array}$

Kingsley et al. (2011); Non RCT

23 women (9 FM and $14 \mathrm{HC}$ ) Age

FM: $42 \pm 5$ years HC: $45 \pm 5$ years

Kayo et al. (2012); RCT

90 women with FM (30 ST, $30 \mathrm{AE}$ and $30 \mathrm{CG})$

Age

Weekly frequency: $3 ; 3$ series of 10 repetitions;

Exercises were not specified,

ST: $46.7 \pm 6.3$ years; however, free weights were used

AE: $47.7 \pm 5.3$ years; and the patient's body weight

CG: $46.1 \pm 6.4$ years Adherence to ST: 73,5

Hooten et al. 72 FM (36 ST and (2012); RCT $36 \mathrm{AE}$
Duration: 16 weeks;

Weekly frequency: 2: 1 serie of 8-12 extension and flexion, Leg press, low ed on machine) Adherence: $82.8 \%$

Duration: 12 weeks:

Weekly frequency: 2; 3 series of 12 repetitions; Intensity: Initially 50\% RM and progressively up to $85 \%$; Exers. Supine, extension and row (performed in machine) Adherence to ST: $88 \%$

Duration: 12 weeks; 1RM Exercises: Supine, extension and flexion of the knee, Leg press, ow row (performed in machine) Adherence to ST: 88\% women with FM, and BRS decreased in controls but not in women with FM.

Both groups increased upper and lower body strength. There were similar improvements in FM impact in both groups. There were no group interactions for the functionality measures. Both groups improved in the strength domains; however, only ST-C significantly improved in the preto postfunctional domains of flexibility, balance and coordination, and endurance.

There was no group-by-time interaction for any variable. Number of active tender points, myalgic score, and FIQ score were decreased after ST in women with FM. Heart rate and natural $\log (\mathrm{Ln})$ high frequency (LnHF) were recovered, whereas Ln low frequency ( $L n L F)$ and $L n L F / L n H F$ ratio were increased 20 min after acute leg resistance exercise. There were no significant effects of ST on HRV at rest or postexercise.

Aortic and digital diastolic blood pressure (DBP) were significantly decreased and aortic and digital pulse pressures (PP) were significantly increased after acute exercise before ST. Acute resistance exercise had no effect on $\mathrm{HR}$, wave reflection (augmentation index and reflection time), digital, or aortic systolic BP. ST improved muscle strength without affecting acute DBP and PP responses.

All 3 groups showed improvement after the 16-week treatment compared to baseline. At the 28-week follow-up, pain reduction was similar for the AE and ST groups, but different from the control group. At the end of the treatment, $80 \%$ of subjects in the control group took pain medication, but only $46.7 \%$ in the $\mathrm{AE}$ and $41.4 \%$ in the ST groups. Mean FIQ total scores were lower for the AE and ST groups compared with the control group.

Significant improvements in pain severity, peak Vo2, strength, and
The ST improved FM impact on quality of life and strength. The practice of chiropractic in conjunction with TF assisted in adherence and functional capacity

The ST increased strength in both groups and reduced pain and number of PT in patients with FM. The practice of ST does not change the resting $H R$, nor the variability of $H R$ compared to healthy subjects.

The results suggest that a legresistance exercise produces post-exercise diastolic hypotension and does not alter aortic systolic blood pressure and HR. In addition, vascular responses at rest and postexercise are not altered after 12 weeks of ST in premenopausal women

The ST was as effective as AE in reducing pain in relation to all study variables.

The ST was effective in reducing pain in relation to all study 
Table 2 Characteristics and results of experimental studies with strength training for patients with fibromyalgia syndrome (Continued)

\begin{tabular}{|c|c|c|}
\hline $\begin{array}{l}\text { Study and } \\
\text { Design }\end{array}$ & Sample & Intervention \\
\hline & $\begin{array}{l}\text { Age } \\
\text { ST } 47.3 \pm \\
10.1 \text { years } \\
\text { AE } 45.8 \pm \\
11.5 \text { years }\end{array}$ & $\begin{array}{l}10 \text { repetitions; } \\
\text { Exercises: Flexion and extension } \\
\text { of the knee and arm } \\
\text { Adherence to ST: } 94,5 \%\end{array}$ \\
\hline $\begin{array}{l}\text { Gavi et al. } \\
\text { (2014); RCT }\end{array}$ & $\begin{array}{l}76 \text { FM }(35 \text { ST and } \\
36 \text { FLEX) } \\
\text { Age } \\
\text { ST: } 44.34 \pm \\
7.94 \text { years } \\
\text { FLEX: } 48.65 \pm \\
7.60 \text { years }\end{array}$ & $\begin{array}{l}\text { Duration: } 16 \text { weeks; } \\
\text { Weekly frequency: } 2 ; 1 \text { serie of } 10 \\
\text { repetitions; Intensity: } 45 \% 1 \mathrm{RM} \\
\text { Exercises: Supine, extension and } \\
\text { flexion of the knee, elbow and } \\
\text { shoulder, Leg press, low paddling, } \\
\text { fly, plantar flexion } \\
\text { Adherence to ST: } 87,5 \%\end{array}$ \\
\hline
\end{tabular}

$\begin{array}{ll}\text { Larsson et al. } & 130 \mathrm{FM} \text { (67 ST, } \\ \text { (2015); RCT } & 63 \mathrm{RT}) \\ & \text { Age } \\ & \text { ST: } 50.81 \pm \\ & 9.05 \text { years; } \\ & \text { RT: } 52.10 \pm \\ & 9.78 \text { years }\end{array}$

$\begin{array}{ll}\text { Palstam } & 67 \text { women } \\ \text { et al. (2016); } & \text { com FM (67 ST) } \\ \text { Non RCT } & \text { Age }\end{array}$
$51 \pm 9.1$ years

$\begin{array}{ll}\text { Ericsson } & 105 \text { women } \\ \text { et al. (2016); } & \text { (56 ST and 49 RT) } \\ \text { RCT } & \text { Range of age } \\ & \text { 22-64 years }\end{array}$
22-64 years

\footnotetext{
Martinsen 54 women (31

et al. (2017); ST and $23 \mathrm{HC}$ ) Age

Non RCT ST: $49 \pm 6$
}

Duration: 15 weeks Weekly frequency: 2 Intensity: increased progressively Exercises: The main muscle groups were worked, but exercises were not specified.

Adherence to ST: $71 \%$
Duration: 15 weeks;

Weekly frequency: 2; Intensity: Initially 40\% 1RM and progressively up to $80 \%$;

Exercises: The main muscle groups were worked, but exercises were not specified.

Adherence to ST: $71 \%$
Duration: 15 weeks;

Weekly frequency: 2; Intensity: Initially 40\% 1RM and progressively up to $80 \%$;

Exercises: The main muscle groups were worked, but exercises were not specified.

Adherence to ST: $71 \%$

Results Conclusion

pain thresholds were observed

from baseline to week 3 in the intent-to-treat analysis; however, patients in the aerobic group experienced greater gains (in peak Vo2) compared to the strength group.

The ST group was more effective to strength gain for all muscles and pain control after 4 and 16 weeks. The FLEX group showed higher improvements in anxiety. Both groups showed improvements in the quality of life, and there was no significant difference observed between the groups. There was no change in the HRV of the ST and FLEX groups.

Significant improvements were found for isometric knee-extension force, health status, current pain intensity, 6MWT, isometric elbow flexion force, pain disability, and pain acceptance in the ST group when compared to the CG. Differed significantly in favor of the ST group at post-treatment examinations. No significant differences between ST group and the active CG were found regarding change in self-reported questionnaires from baseline to 13-18 months.

Reduced pain disability was explained by higher pain disability at baseline together with decreased fear avoidance beliefs about physical activity. The improvements in the disability domains of recreation and social activity were explained by decreased fear avoidance beliefs about physical activity together with higher baseline values of each disability domain respectively. The improvement in occupational disability was explained by higher baseline values of occupational disability.

A higher improvement was found at the post-treatment examination for change in the ST group; as compared to change in the active CG in the MFI-20 subscale of physical fatigue. Sleep efficiency was the strongest predictor of change in the MFI-20 subscale general fatigue. Participating in resistance exercise and working fewer hours per week were independent significant predictors of change in physical fatigue.

The FIQ ratings decreased following exercise in patients with FM, suggesting an improvement of FM symptoms. Furthermore, for the variables. ST practice reduced pain significantly, but there was no difference in relation to $\mathrm{AE}$.

There was an increase in functionality, depression, quality of life in both groups, with no statistical difference between them. There was greater reduction of pain in the ST group.

The ST was considered a viable exercise mode for women with FM, improving muscle strength, with a significant improvement in health-related quality of life and current pain intensity, when assessed immediately a fter the intervention.

The ST reduces pain, inability and fear of practicing Physical exercises and increased strength and level of physical activity.

The ST group significantly reduced general, physical and mental fatigue and improved sleep efficiency in relation to the relaxation group; depression and anxiety did not decline after the intervention

The intervention had different effects on the speed of cognitive processing during SCWT in patients with FM and
Weekly frequency: 2

Exercises: exercises were not specified. 
Table 2 Characteristics and results of experimental studies with strength training for patients with fibromyalgia syndrome (Continued)

\begin{tabular}{|c|c|c|c|}
\hline $\begin{array}{l}\text { Study and } \\
\text { Desian }\end{array}$ & Sample & Intervention & Results \\
\hline & $\mathrm{HC}: 47 \pm 2$ & Adherence to ST: $65,5 \%$ & $\begin{array}{l}\text { SF-36 PCS ratings we found a } \\
\text { statistically significant effect of } \\
\text { group and intervention, but no } \\
\text { significant interaction between } \\
\text { the factors, thus showing that } \\
\text { exercise improved ratings of } \\
\text { SF-36 PCS in both groups. }\end{array}$ \\
\hline
\end{tabular}

$\begin{array}{ll}\text { Andrade, } & \text { 52 FM (31 ST and } \\ \text { Vilarino e } & \text { 21 CG) } \\ \text { Bevilacqua } & \text { Age } \\ \text { (2017); Non } & \text { ST: } 54.42 \pm 7.16 \\ \text { RCT } & \text { CG: } 53.10 \pm 8\end{array}$

RCT CG: $53.10 \pm 8$
Duration: 8 weeks

Weekly frequency: 3 Exercises: knee extension, knee flexion, bench press, fly, adductors, low rowing, high pulley, elbow extension, lateral raise, arm curl, standing calf raise, and abdominal crunch. Adherence to ST: 81,5

$\begin{array}{ll}\text { Assumpção } & 53 \text { FM (19 ST, } 18 \\ \text { et al. (2017); } & \text { FLEX E 16 CG) } \\ \text { RCT } & \text { Age } \\ & \text { ST: } 45.7 \pm 7.7 \\ & \text { FLEX: } 47.9 \pm 5.3 \\ & \text { CG: } 46.9 \pm 6.5\end{array}$

Duration: 12 weeks

Weekly frequency: 2

Exercises: eight repetitions of strengthening exercises for the following muscles triceps sural, hip adductors and abductors, hip flexor, shoulder flexor and extensor, anterior and posterior deltoids, pectoralis major and rhomboids Adherence to ST: $89,5 \%$
After 8 weeks of intervention, significant differences were found between groups in subjective quality of sleep, sleep disturbance, daytime dysfunction, and total sleep score. The correlation analysis using Spearman's test indicated a positive relationship between the variables of pain intensity and sleep quality; when pain intensity increased in patients with fibromyalgia, sleep quality worsened.

The ST group had the lowest depression score and; the control had the highest score of morning tiredness and stiffness, and the lowest score of vitality. In the clinical analyses, the stretching group had important improvement in quality of life for all SF-36 domains, and the strengthening group had important improvements in the impact on FM symptoms measured by the FIQ total score and in the quality of life for SF-36 domains of physical functioning, vitality, social function, role emotional and mental health.
Conclusion

\author{
healthy controls. We found \\ evidence of increased amygdala \\ activation. In contrast, HC \\ showed decreased RTs in \\ incongruent and congruent \\ stimuli. Exercise had no effect \\ on distraction-induced analgesia \\ or pressure pain thresholds in \\ any of the groups but decreased \\ the overall severity of FM \\ symptoms.
}

A significant relationship was found between pain level and sleep disturbances in FM patients, and it was found that the higher the pain, the worse the sleep quality of these patients. The ST group reduced levels of sleep disturbance after 8 weeks of intervention.

The ST was more effective to reducing depression, while stretching exercises was better to improving quality of life, especially physical functioning and pain.

LEGEND: FM Fibromyalgia, HC Healthy Control, RCT Controlled and Randomized Study, TP Tender Points, AE Aerobic Group, RT Relaxation Therapy, RM 1 Maximum Repeat, ST Strength Training, ST-C Strength Training and chiropractic, FLEX Flexibility training, HR Heart Rate, HRV Heart Rate Variability, CG Control Group, NMS Neuro-muscular system, SCWT Test of colored words Stroop, RTs long reaction times, FIQ Fibromyalgia Impact Questionnaire, SF-36 36 - Item Short Form Survey, PCS Physical Component, MCS Mental Components, HAD Hospital Anxiety and Depression Score, 6 MWT 6 min walking test, PGIC patient global impression of change, VAS Visual Analogue Scale, MFI-20 Multidimensional Fatigue Inventory, CSA cross-sectional area, QF quadriceps femoris, LF low-frequency, GH growth hormone, HAQ Health Assessment Questionnaire, EMG Surface electromyographic, Hfnu normalized high-frequency, Lfnu normalized low-frequency, RTs reaction times

has favorable results, such as reducing physical and psychological symptoms. However, there are still gaps that need to be investigated.

Concerning the ST sessions, it was observed that there is no specific training protocol for patients with FM; thus, the researchers developed their own protocol. Jones et al. [45] submitted the patients to a series of four to five repetitions, progressively increasing the number of repetitions up to 12 . This protocol was similar to that used by Bircan et al. [42], who instructed patients to perform a series of four repetitions and progressively increased the repetitions by up to 12. Kingsley et al. [28] and Figueroa et al. [49] also submitted the patients to a series in each exercise; however, from the beginning of the intervention, the patients were instructed to perform from 8 to 12 repetitions. As the first studies analyzed were published in 2001 and 2002, and at that time there was little knowledge about the development of the disease and the effects of ST on the patients, those first studies chose to use low load and series. On the basis of the results of the earlier studies, more studies were performed and chose to use more series with more repetitions from the beginning [24, 27, $44,48]$. Despite some differences in the protocols, the intensity of the exercises increased gradually. In some studies, the intensity reached $80 \%$ of $1 \mathrm{RM}$ at the end of the intervention [25, 27]. Another issue concerns weekly 


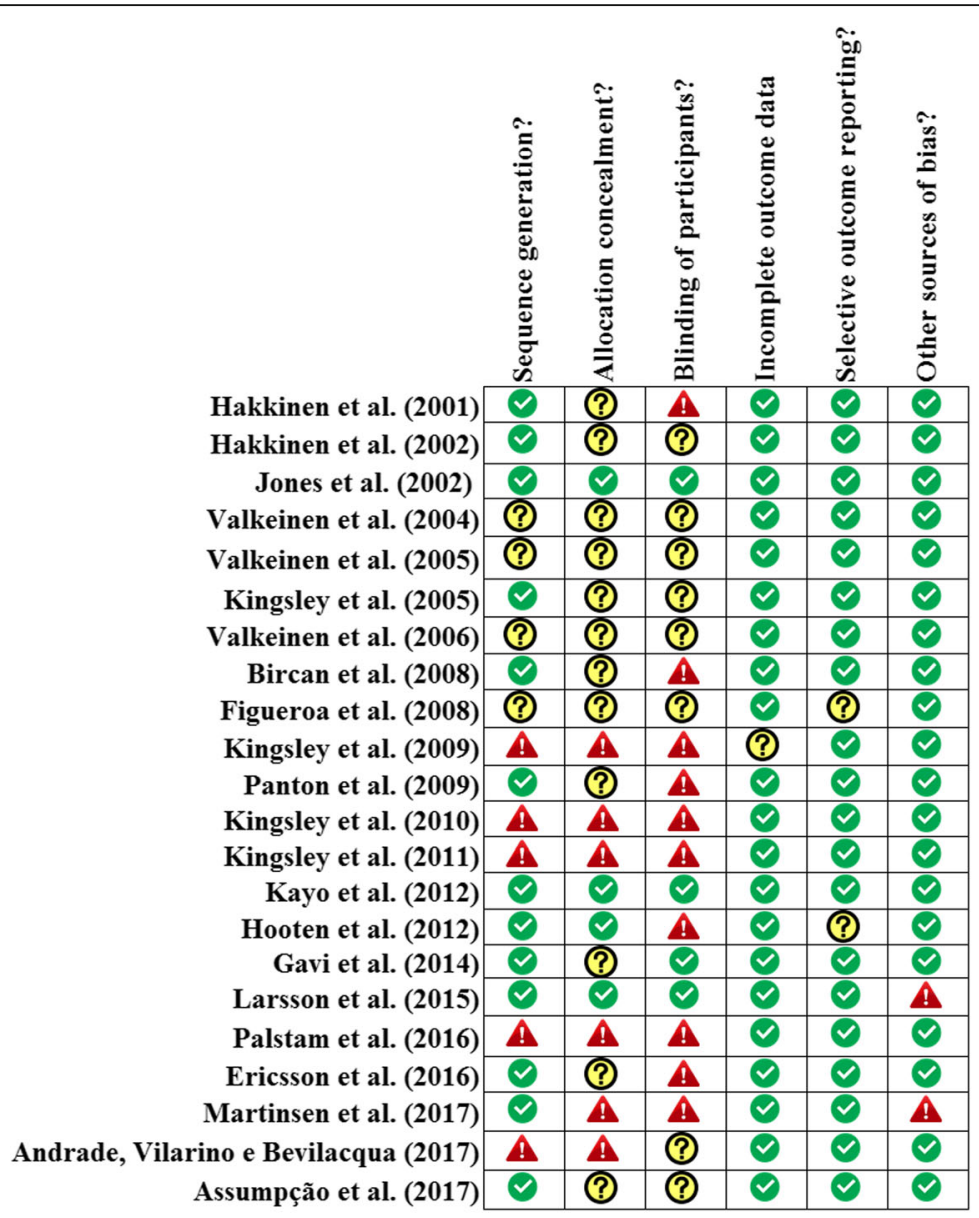

LEGEND: $\diamond$ LOW RISK $\triangle$ HIGH RISK ? UNCLEAR RISK

Fig. 2 Risk of bias in the studies analyzed

frequency, but this differed slightly between 2 and 3 weekly sessions. Despite the differences in the protocols, it was observed that, in general, the studies followed the recommendations of the American College of Sports Medicine for beginners in ST.

With regard to the main symptoms, there was a greater interest in pain, strength, quality of life, HRV, and depression. Pain is the main symptom of FM and is associated with other symptoms such as depression, sleep disorders, and poor quality of life [24, 56]; thus, finding treatments that improve these symptoms are of crucial clinical relevance for patients. The results of the present review demonstrate that the pain of patients with FM is significantly reduced by the ST intervention. Valkeinen et al. [53] evaluated 23 women with FM, of whom 13 were submitted to 2 ST sessions for 21 weeks and 10 were part of the control group. At the end of the 21 weeks of intervention, significant improvement in pain was observed. Other studies examined the effect of shorter periods of ST, and found that pain can be reduced in a short time. Hooten et al. [30] analyzed the effect of 3-week ST on pain. Participants performed 2 weekly sessions, consisting of a series of 10 repetitions of knee and elbow flexion and extension exercises. At the end of the study, a significant reduction of pain was observed. This result is interesting for health professionals and for patients with FM, because it demonstrates that ST can help reduce symptoms in a few weeks and with few exercises.

Studies indicate that patients with FM have less strength and reduced functional capacity compared with healthy persons of the same age and without the disease [57]. The reduced muscle strength of patients with FM may be related to pain; because of pain, it is common for patients to avoid making physical efforts. However, studies that aimed to verify the responses of patients with FM after muscular effort showed positive results. In studies that applied ST, strength and hypertrophy were similar between patients with and those without the disease. 
The first studies in this sense were those of Hakkinen et al. [38], Hakkinen et al. [51], Valkeinen et al. [41] and Valkeinen et al. [52]. The first 2 studies analyzed the effect of 21-week ST in patients with FM, and compared the results with those of healthy persons. From the results of these studies, it can be observed that there was an increase of force, activation, and hypertrophy in the ST group and in controls. Hakkinen et al. [51] verified an increase of $18 \%$ in the muscular strength of patients with FM, and of $22 \%$ in the control group, concluding that the neuromuscular adaptations derived from ST are similar between patients with FM and healthy persons. Reinforcing this result, Valkeinen et al. [41] observed a significant increase of the strength in the extension and flexion of the knee in patients with FM [33\% and 20\%, respectively], whereas in the control group the gains were $12 \%$ and $17 \%$, respectively. Valkeinen et al. [52] that analyzed strength found that after 21 weeks of ST, patients with FM had a $36 \%$ increase in isometric force and $33 \%$ in concentric force. In addition, the authors verified a $5 \%$ increase in the cross-sectional area of the thigh and increased activation by $57 \%$. After analyzing the results, the authors concluded that ST is safe for patients with FM and that the patients can undergo training with higher intensities.

Another variable that was investigated in the studies was the HRV. Some authors suggested that FM occurs because of dysregulation of the central nervous system [6, $8]$, causing an autonomic dysfunction that induces the appearance of some symptoms such as fatigue and anxiety. Figueroa et al. [49] verified the heart rate behavior of patients with FM who also had autonomic dysfunction. The researchers subjected the patients to 16 weeks of ST and verified improvements in HRV, parasympathetic activity, and pain reduction. Kingsley et al. [27] compared the effects of 12 weeks of ST on patients with FM and healthy women, in terms of various symptoms such as pain, number of tender points, impact of FM on quality of life, and HRV. The results showed an increase in strength in both groups, besides the reduction of pain and tender points in patients with FM; however, in terms of the behavior of HRV, no significant difference was observed between patients with FM and the healthy group. In contrast, in the study of Kingsley et al. [43] that aimed to verify the autonomic modulation of patients with FM after a ST session, the results demonstrated that patients with FM had a lower sympathetic response and greater vagal modulation, without altering the baroreflex sensitivity, a response different from that presented by the control group. Concerning a possible autonomic dysfunction in patients with FM, further studies need to be carried out in order to reach a conclusion.

Other symptoms investigated were quality of life, depression, and sleep disturbance. As quality of life is a variable that is directly related to other symptoms, the improvements observed in the other symptoms suggest that the quality of life could also be expected to increase. In the study of Gavi et al. [29], significant improvements in pain, functionality, quality of life, and depression were found after 16 weeks of ST. Similar results were found by Larsson et al. [54] and Palstam et al. [55]. In the first study, there was a reduction in pain and an increase in strength and quality of life. In the second study, in addition to the results seen in previous studies, the researchers noticed a reduction in the fear of performing exercises. With regard to sleep disturbance, some studies found a reduction after ST intervention [24, 25]. In addition, sleep quality correlated with pain, with patients having less pain experiencing less sleep disorders [24].

With the new possibility of using ST as an alternative treatment for patients with FM, some researchers began to compare the effects of ST with those of other physical exercise interventions. In the study of Bircan et al. [42], 13 women with FM were submitted to aerobic exercise and 13 were submitted to ST. The researchers found that both interventions have benefits for patients, including reduction of pain, fatigue, sleep disorders, and depression, and improvement of aerobic capacity. However, no significant improvements in anxiety were observed in either group. In the studies by Kayo et al. [48] and Hooten et al. [30], the effects of ST were also compared with those of aerobic exercise. It was noted that the 2 interventions presented similar results, particularly in reducing the pain of patients. In addition, other studies compared ST with relaxation or flexibility exercises. Assumpção et al. [40] verified the effects of ST and flexibility exercises after 12 weeks of intervention. The results demonstrated that ST is more effective in reducing depression, whereas flexibility exercises are better at improving the quality of life, especially physical function and pain. Gavi et al. [29] found similar results: ST and flexibility training were effective for reducing symptoms; however, the best results in terms of pain were found in the ST group. The study of Jones et al. [45] also compared ST and flexibility training, and verified that both interventions are effective; however, the most significant results were found in the ST group. Lorena et al. [58] performed a systematic review on the effects of stretching in patients with FM, and reported the importance of this intervention in improving the physical and mental aspects of patients. Nevertheless, they emphasized the need for studies with greater methodological rigor. The same can be emphasized in the present review: the positive effect of ST in patients with FM is visible, but it is necessary to carry out more studies with greater methodological rigor to address possible gaps.

Another interesting result is about adherence to treatments. It is known that patients with FM have difficulties 
adhering to the practice of physical exercise; however, few studies reported the adherence of patients to the interventions $[59,60]$. In the present review, the mean adherence percentage was $84 \%$, a result similar to that of the study by Sanz-Baños et al. [59] in patients undergoing aerobic exercises [adherence percentage $87.2 \%$ ]. This result is a further indication that ST can be used as part of the treatment for patients with FM, because in addition to improving the symptoms, the patients show high adherence to the intervention.

Concerning the strengths and limitations of the study, we were able to verify through a broad literature review that ST improves the symptoms of patients with FM; however, some studies presented a high risk of bias and further studies are needed to consolidate the obtained results. In addition, future reviews including the gray literature are warranted in order to identify other studies on the subject.

\section{Conclusion}

In conclusion, ST had positive effects on physical and psychological symptoms, in terms of reducing pain, the number of tender points, and depression, and improving muscle strength, sleep quality, functional capacity, and quality of life. Intervention protocols should start at low intensity (40\% of $1 \mathrm{RM})$ and gradually increase the intensity. ST should be performed 2 or 3 times a week to exercise the main muscle groups. The current studies showed that ST is a safe and effective method of improving the major symptoms of FM and can be used to treat patients with this condition.

\section{Additional file}

Additional file 1: Search strategies at PubMed. (PDF $94 \mathrm{~kb}$ )

\section{Abbreviations}

1RM: One maximum repetition; FM: Fibromyalgia; HRV: Heart Rate Variability; PE: Physical Activity; ST: Strength Training

\section{Acknowledgments}

The authors thank FAPESC (Foundation for Research and Innovation of the State of Santa Catarina) for financial support through a research grant (Project No. 2442-2011/12), CAPES for a Master scholarship (grant No. 02/2017), and the State University of Santa Catarina for a UDESC study opportunity.

\section{Funding}

Foundation for Research and Innovation of the State of Santa Catarina grant (Project No. 2442-2011/12).

\section{Authors' contributions}

A.A., S.R.A.K, S.S.M, T.L.A.P drafted the manuscript. S.R.A.K, V.T.G., S.S.M., carried out the analysis. All authors discussed the results, commented on the manuscript and approved the final draft of the manuscript.

Ethics approval and consent to participate Not applicable.
Consent for publication

Not applicable.

\section{Competing interests}

Alexandro Andrade, Ricardo de Azevedo Klumb Steffens, Sofia Mendes Sieczkowska, Leonardo Alexandre Peyré Tartaruga and Guilherme Torres Vilarino declare that they have no conflict of interest.

\section{Publisher's Note}

Springer Nature remains neutral with regard to jurisdictional claims in published maps and institutional affiliations.

\section{Author details}

${ }^{1}$ Health and Sports Science Center, CEFID / Santa Catarina State University UDESC, Florianópolis, SC, Brazil. 'Laboratory of Sports and Exercise Psychology - LAPE, Florianópolis, SC, Brazil. ${ }^{3}$ Regional University of Blumenau - FURB, Blumenau, SC, Brazil. ${ }^{4}$ Human Movement Sciences and Pneumological Sciences, UFRGS- Federal University of Rio Grande do Sul, Porto Alegre, RS, Brazil. ${ }^{5}$ Research Laboratory of Exercise - LAPEX, Porto Alegre, RS, Brazil.

Received: 23 March 2018 Accepted: 28 September 2018 Published online: 22 October 2018

References

1. Wolfe F, Smythe HA, Yunus MB, Bennett RM, Bombardier C, Goldenberg DL, et al. The American College of Rheumatology 1990 criteria for the classification of fibromyalgia. Arthritis Rheum. 1990;33(2):160-72.

2. Wolfe F, Clauw DJ, Fitzcharles M-A, Goldenberg DL, Häuser W, Katz RL, et al. 2016 Revisions to the 2010/2011 fibromyalgia diagnostic criteria. Seminars in arthritis and rheumatism. 2016:46:319-29.

3. Wolfe F, Clauw DJ, Fitzcharles MA, Goldenberg DL, Katz RS, Mease P, et al. The American College of Rheumatology Preliminary Diagnostic Criteria for fibromyalgia and measurement of symptom severity. Arthritis Care Res. 2010;62(5):600-10 PubMed PMID: WOS:000280979600004.

4. Borchers AT, Gershwin ME. Fibromyalgia: a critical and comprehensive review. Clin Rev Allergy Immunol. 2015;49(2):100-51 PubMed PMID:WOS: 000362902500002.English.

5. McDowell CP, Cook DB, Herring MP. The effects of exercise training on anxiety in fibromyalgia patients: a meta-analysis. Med Sci Sports Exerc. 2017 ; 49(9):1868-76 PubMed PMID: 28419024.Epub 2017/04/19.eng.

6. Häuser W, Ablin J, Fitzcharles M-A, Littlejohn G, Luciano JV, Usui C, et al. Fibromyalgia. Nature reviews Disease primers. 2015;1:15022.

7. Andrade A, Vilarino GT, Sieczkowska SM, Coimbra DR, Steffens RAK, Vietta GG. Acute effects of physical exercises on the inflammatory markers of patients with fibromyalgia syndrome: a systematic review. J Neuroimmunol. 2018;316:40-9.

8. Sluka KA, Clauw DJ. Neurobiology of fibromyalgia and chronic widespread pain. Neuroscience. 2016;338:114-29 PubMed PMID:WOS:000386338200008.English.

9. Hauser W, Klose P, Langhorst J, Moradi B, Steinbach M, Schiltenwolf M, et al. Efficacy of different types of aerobic exercise in fibromyalgia syndrome: a systematic review and meta-analysis of randomised controlled trials. Arthritis Res Ther. 2010;12(3):R79 PubMed PMID: 20459730. PMCID: PMC2911859. Epub 2010/05/13.eng.

10. Arnold LM. Biology and therapy of fibromyalgia - New therapies in fibromyalgia. Arthritis Res Ther. 2006;8(4):20 PubMed PMID: WOS: 000240985200002.English.

11. Hauser W, Bernardy K, Arnold B, Offenbacher M, Schiltenwolf M. Efficacy of multicomponent treatment in fibromyalgia syndrome: a meta-analysis of randomized controlled clinical trials. Arthritis Rheum. 2009;61(2):216-24 PubMed PMID: 19177530. Epub 2009/01/30.eng.

12. Poole $\mathrm{J}$, Siegel $P$. Effectiveness of occupational therapy interventions for adults with fibromyalgia: a systematic review. Am J Occup Ther. 2017;71(1): 7101180040p1-p10 PubMed PMID: 28027041. Epub 2016/12/28.eng.

13. Sanz-Baños Y, Pastor-Mira MÁ, Lledó A, López-Roig S, Peñacoba C, \& Sánchez-Meca, J. Do women with fibromyalgia adhere to walking for exercise programs to improve their health? Systematic review and metaanalysis. Disabil Rehabil. 2018;40(21):2475-87.

14. Bidonde J, Busch AJ, Schachter CL, Overend TJ, Kim SY, Góes SM, et al. Aerobic exercise training for adults with fibromyalgia. Cochrane Libr. 2017.

15. Brosseau L, Wells GA, Tugwell P, Egan M, Wilson KG, Dubouloz CJ, et al. Ottawa Panel evidence-based clinical practice guidelines for aerobic fitness 
exercises in the management of fibromyalgia: part 1. Phys Ther. 2008;88(7): 857-71 PubMed PMID: 18497301. Epub 2008/05/24. eng.

16. Brosseau L, Wells GA, Tugwell P, Egan M, Wilson KG, Dubouloz CJ, et al. Ottawa panel evidence-based clinical practice guidelines for strengthening exercises in the management of fibromyalgia: part 2. Phys Ther. 2008;88(7): 873-86 PubMed PMID: WOS:000257473000008. English

17. Busch AJ, Webber SC, Richards RS, Bidonde J, Schachter CL, Schafer LA, et al. Resistance exercise training for fibromyalgia. Cochrane Database Syst Rev. 2013;(12):113 PubMed PMID: WOS:000329188500042. English.

18. Segura-Jimenez V, Castro-Pinero J, Soriano-Maldonado A, Alvarez-Gallardo IC, Estevez-Lopez F, Delgado-Fernandez M, et al. The association of total and central body fat with pain, fatigue and the impact of fibromyalgia in women; role of physical fitness. Eur J Pain. 2016;20(5):811-21 PubMed PMID: WOS:000373997600014.

19. Musumeci G. Effects of exercise on physical limitations and fatique in rheumatic diseases. World J Orthop. 2015;6(10):762-9 PubMed PMID: 26601057. PMCID: 4644863. eng.

20. Segura-Jimenez V, Alvarez-Gallardo IC, Carbonell-Baeza A, Aparicio VA, Ortega FB, Casimiro AJ, et al. Fibromyalgia has a larger impact on physical health than on psychological health, yet both are markedly affected: the alAndalus project. Semin Arthritis Rheum. 2015;44(5):563-70 PubMed PMID: WOS:000352923200013. English.

21. Nelson NL. Muscle strengthening activities and fibromyalgia: a review of pain and strength outcomes. J Bodyw Mov Ther. 2015;19(2):370-6 PubMed PMID: 25892394. Epub 2015/04/22. eng.

22. Bidonde J, Jean Busch A, Bath B, Milosavljevic S. Exercise for adults with fibromyalgia: an umbrella systematic review with synthesis of best evidence. Curr Rheumatol Rev. 2014;10(1):45-79.

23. Jones KD. Recommendations for resistance training in patients with fibromyalgia. Arthritis Res Ther. 2015;17(1):258.

24. Andrade A, Vilarino GT, Bevilacqua GG. What is the effect of strength training on pain and sleep in patients with fibromyalgia? Am J Phys Med Rehabil. 2017.

25. Ericsson A, Palstam A, Larsson A, Lofgren M, Bileviciute-Ljungar I, Bjersing J, et al. Resistance exercise improves physical fatigue in women with fibromyalgia: a randomized controlled trial. Arthritis Res Ther. 2016;18:12 PubMed PMID: WOS:000381728500002. English.

26. Larsson A, Palstam A, Lofgren M, Ernberg M, Bjersing J, Bileviciute-Ljungar I, et al. Resistance exercise improves muscle strength, health status and pain intensity in fibromyalgia--a randomized controlled trial. Arthritis Res Ther. 2015;17:161 PubMed PMID: 26084281. PMCID: PMC4489359. Epub 2015/ 06/19. eng

27. Kingsley JD, McMillan V, Figueroa A. The effects of 12 weeks of resistance exercise training on disease severity and autonomic modulation at rest and after acute leg resistance exercise in women with fibromyalgia. Arch Phys Med Rehabil. 2010;91(10):1551-7 PubMed PMID: WOS:000282720300010. English.

28. Kingsley JD, Panton LB, Toole T, Sirithienthad P, Mathis R, McMillan V. The effects of a 12-week strength-training program on strength and functionality in women with fibromyalgia. Arch Phys Med Rehabil. 2005; 86(9):1713-21 PubMed PMID: WOS:000231747300001.

29. Gavi M, Vassalo DV, Amaral FT, DCF M, Gava PL, Dantas EM, et al. Strengthening exercises improve symptoms and quality of life but do not change autonomic modulation in fibromyalgia: a randomized clinical trial. PLoS One. 2014;9(3):-8 PubMed PMID: WOS:000333352800023. English.

30. Hooten WM, Qu WC, Townsend CO, Judd JW. Effects of strength vs aerobic exercise on pain severity in adults with fibromyalgia: A randomized equivalence trial. Pain. 2012;153(4):915-923. PubMed PMID: WOS: 000301877300027. English

31. Panton LB, Figueroa A, Kingsley JD, Hornbuckle L, Wilson J, St John N, et al. Effects of resistance training and chiropractic treatment in women with fibromyalgia. J Altern Complement Med. 2009;15(3):321-8 PubMed PMID: 19249999. Epub 2009/03/03. eng.

32. Moher D, Shamseer L, Clarke M, Ghersi D, Liberati A, Petticrew M, et al. Preferred reporting items for systematic review and meta-analysis protocols (PRISMA-P) 2015 statement. Syst Rev. 2015;4(1):1.

33. Urrútia G, Bonfill X. La Declaración PRISMA: un paso adelante en la mejora de las publicaciones de la Revista Española de Salud Pública. Rev Española Salud Públ. 2013:87(2):99-102.

34. Booth A, Clarke M, Dooley G, Ghersi D, Moher D, Petticrew M, et al. The nuts and bolts of PROSPERO: an international prospective register of systematic reviews. Syst Rev. 2012;1 (1):2.
35. Moher D, Booth A, Stewart L. How to reduce unnecessary duplication: use PROSPERO. Bjog-an International Journal of Obstetrics and Gynaecology. 2014;121(7):784-6 PubMed PMID: WOS:000336445300032.

36. Higgins JP, Altman DG, Gotzsche PC, Juni P, Moher D, Oxman AD, et al. The Cochrane Collaboration's tool for assessing risk of bias in randomised trials. BMJ (Clinical research ed). 2011;343:d5928. PubMed PMID: 22008217. PMCID: PMC3196245. Epub 2011/10/20. eng.

37. Cohen J. A coefficient of agreement for nominal scales. Educ Psychol Meas. 1960;20(1):37-46.

38. Hakkinen A, Hakkinen K, Hannonen P, Alen M. Strength training induced adaptations in neuromuscular function of premenopausal women with fibromyalgia: comparison with healthy women. Ann Rheum Dis. 2001;60(1): 21-6 PubMed PMID: WOS:000166008100005. English.

39. Martinsen S, Flodin P, Berrebi J, Lofgren M, Bileviciute-Ljungar I, Mannerkorp $\mathrm{K}$, et al. The role of long-term physical exercise on performance and brain activation during the Stroop colour word task in fibromyalgia patients. Clin Physiol Funct Imaging. 2017; PubMed PMID: 28627125. Epub 2017/ 06/20. eng.

40. Assumpção A ML, Yuan SL, Santos AS, Sauer J, Mango P, Marques AP. Muscle stretching exercises and resistance training in fibromyalgia: which is better? A three-arm randomized controlled trial. - PubMed - NCBI. 2017.

41. Valkeinen $\mathrm{H}$, Alen M, Hannonen P, Hakkinen A, Airaksinen O, Hakkinen K. Changes in knee extension and flexion force, EMG and functional capacity during strength training in older females with fibromyalgia and healthy controls. Rheumatology. 2004;43(2):225-8 PubMed PMID: WOS: 000188850000018. English.

42. Bircan C, Karasel SA, Akgun B, El O, Alper S. Effects of muscle strengthening versus aerobic exercise program in fibromyalgia. Rheumatol Int. 2008;28(6): 527-32 PubMed PMID: WOS:000254206100004. English.

43. Kingsley JD, Panton LB, McMillan V, Figueroa A. Cardiovascular autonomic modulation after acute resistance exercise in women with fibromyalgia. Arch Phys Med Rehabil. 2009;90(9):1628-34 PubMed PMID: WOS:000269938100023.

44. Kingsley JD, McMillan V, Figueroa A. Resistance exercise training does not affect post-exercise hypotension and wave reflection in women with fibromyalgia. Appl Physiol Nutr Metab. 2011;36:254-63 PubMed PMID: WOS:000209142901618.

45. Jones KD, Burckhardt CS, Clark SR, Bennett RM, Potempa KM. A Randomized controlled trial of muscle strengthening versus flexibility training in fibromyalgia. J Rheumatol. 2002;29(5):1041-8 PubMed PMID: WOS: 000175430100030 . English.

46. Rooks DS, Silverman CB, Kantrowitz FG. The effects of progressive strength training and aerobic exercise on muscle strength and cardiovascular fitness in women with fibromyalgia: a pilot study. Arthritis Rheum-Arthritis Care Res. 2002;47(1):22-8 PubMed PMID: WOS:000173803700005. English.

47. Rooks DS, Gautam S, Romeling M, Cross ML, Stratigakis D, Evans B, et al. Group exercise, education, and. combination self-management in women with fibromyalgia - A randomized trial. Arch Intern Med. 2007;167(20):2192200 PubMed PMID: WOS:000250806200005. English.

48. Kayo AH, Peccin MS, Sanches CM, Trevisani VF. Effectiveness of physical activity in reducing pain in patients with fibromyalgia: a blinded randomized clinical trial. Rheumatol Int. 2012;32(8):2285-92 PubMed PMID: 21594719. Epub 2011/05/20.eng.

49. Figueroa A, Kingsley JD, McMillan V, Panton LB. Resistance exercise training improves heart rate variability in women with fibromyalgia. Clin Physiol Funct Imaging. 2008;28(1):49-54 PubMed PMID: WOS:000251629100008.

50. Kingsley JD, McMillan V, Figueroa A. Resistance Exercise Training Does Not Affect Post-exercise Hypotension And Wave Reflection In Women With Fibromyalgia. J Gen Intern Med. 2012;27:458 PubMed PMID: WOS:000209142901618.

51. Hakkinen K, Pakarinen A, Hannonen P, Hakkinen A, Airaksinen O, Valkeinen $\mathrm{H}$, et al. Effects of strength training on muscle strength, cross-sectional area, maximal electromyographic activity, and serum hormones in premenopausal women with fibromyalgia. Journal of Rheumatology. 2002; 29(6):1287-95 PubMed PMID: WOS:000176033500028.

52. Valkeinen $\mathrm{H}$, Hakkinen $\mathrm{K}$, Pakarinen $\mathrm{A}$, Hannonen $\mathrm{P}$, Hakkinen $\mathrm{A}$, Airaksinen $\mathrm{O}$, et al. Muscle hypertrophy, strength development, and serum hormones during strength training in elderly women with fibromyalgia. Scand J Rheumatol. 2005;34(4):309-14 PubMed PMID: WOS:000231312100009.

53. Valkeinen $\mathrm{H}$, Hakkinen $\mathrm{A}$, Hannonen $\mathrm{P}$, Hakkinen $\mathrm{K}$, Alen M. Acute heavyresistance exercise-induced pain and neuromuscular fatigue in elderly 
women with fibromyalgia and in healthy controls - effects of strength training. Arthritis Rheum. 2006;54(4):1334-9 PubMed PMID: WOS: 000236830800035. English.

54. Larsson A, Palstam A, Lofgren M, Ernberg M, Bjersing J, Bileviciute-Ljungar I, et al. Resistance exercise improves muscle strength, health status and pain intensity in fibromyalgia-a randomized controlled trial. Arthritis Research \& Therapy. 2015;17:15 PubMed PMID: WOS:000357248900001. English.

55. Palstam A, Larsson A, Lofgren M, Ernberg M, Bjersing J, Bileviciute-Ljungar I, et al. Decrease of fear avoidance beliefs following person-centered progressive resistance exercise contributes to reduced pain disability in women with fibromyalgia: secondary exploratory analyses from a randomized controlled trial. Arthritis Research \& Therapy. 2016;18 PubMed PMID: WOS:000376372300006.

56. Andrade A, Vilarino GT, Sieczkowska SM, Coimbra DR, Bevilacqua GG, Steffens RAK. The relationship between sleep quality and fibromyalgia symptoms. J Health Psychol. 2018. https://doi.org/10.1177/1359105317751615.

57. Larsson A, Palstam A, Bjersing J, Löfgren M, Ernberg M, Kosek E, et al. Controlled, cross-sectional, multi-center study of physical capacity and associated factors in women with fibromyalgia. BMC Musculoskelet Disord. 2018;19(1):121

58. Lorena SB, Lima Mdo C, Ranzolin A, Duarte AL. Effects of muscle stretching exercises in the treatment of fibromyalgia: a systematic review. Rev Bras Reumatol 2015;55(2):167-173. PubMed PMID: 25440706. Epub 2014/12/ 03. eng.

59. Sanz-Banos Y, Pastor-Mira MA, Lledo A, Lopez-Roig S, Penacoba C, SanchezMeca J. Do women with fibromyalgia adhere to walking for exercise programs to improve their health? Systematic review and meta-analysis. Disabil Rehabil. 2017;07:1-13 PubMed PMID: 28687050. Epub 2017/07/09. eng.

60. Thomas EN, Blotman F. Aerobic exercise in fibromyalgia: a practical review. Rheumatol Int. 2010;30(9):1143-50 PubMed PMID: 20340025. Epub 2010/03/27. eng.

Ready to submit your research? Choose BMC and benefit from:

- fast, convenient online submission

- thorough peer review by experienced researchers in your field

- rapid publication on acceptance

- support for research data, including large and complex data types

- gold Open Access which fosters wider collaboration and increased citations

- maximum visibility for your research: over $100 \mathrm{M}$ website views per year

At $\mathrm{BMC}$, research is always in progress.

Learn more biomedcentral.com/submissions 